\title{
Global Mental Health: concepts, conflicts and controversies
}

\author{
Rob Whitley* \\ Department of Psychiatry, Douglas Mental Health University Institute, McGill University, 6875, boulevard LaSalle, Verdun (Québec), H4H 1R3, \\ Canada
}

\begin{abstract}
This paper introduces, describes and analyses the emerging concept of Global Mental Health (GMH). The birth of GMH can be traced to London, 2007, with the publication of a series of high-profile papers in The Lancet. Since then, GMH has developed into a movement with proponents, adherents, opponents, an ideology and core activities. The stated aims of the Movement for GMH are 'to improve services for people living with mental health problems and psychosocial disabilities worldwide, especially in low- and middle-income countries where effective services are often scarce'. GMH could be considered an attempt to right a historic wrong. During the colonial and post-colonial eras, the mental health of subject populations was accorded a very low priority. This was fuelled by scientific racism, which alleged that mental illness was uncommon in places such as Africa. As developing nations have made the epidemiological transition, the burden of mental illness has proportionately increased, with research suggesting a massive 'treatment gap' between those in need and those actually receiving formal mental health care. As such, much GMH research and action has been devoted to: (i) the identification and scale-up of cost-effective evidence-supported interventions that could be made more widely available; (ii) task-shifting of such intervention delivery to mental-health trained non-specialist Lay Health Workers. GMH has come under sustained critique. Critics suggest that GMH is colonial medicine come full circle, involving the top-down imposition of Western psychiatric models and solutions by Western-educated elites. These critiques suggest that GMH ignores the various indigenous modalities of healing present in non-Western cultures, which may be psychologically adaptive and curative. Relatedly, critics argue that GMH could be an unwitting Trojan horse for the mass medicalisation of people in developing countries, paving the way for exploitation by Big Pharma, while ignoring social determinants of health.
\end{abstract}

Key words: Cultural psychiatry, Epidemiology, Global Mental Health, medical anthropology, public health.

\section{Introduction}

Psychiatry began as a separate medical discipline during the 19th century (Shorter, 1997). Throughout this period, European and American psychiatrists had shown a particular interest in the mental health of non-Western people. In 1851, American psychiatrist Samuel Cartwright declared that black slaves fleeing captivity were suffering from a mental illness called drapetomania (Cartwright, 1851). Kraepelin (1921) travelled to Java, writing that local people rarely displayed signs of depression, which he attributed to their 'psychic underdevelopment'. These early accounts were permeated with patronising language and scientific racism. Thus began the tradition of Western psychiatrists investigating and treating mental illness and emotional suffering in non-Western people.

That said, some efforts were made to alleviate suffering and provide for people with alleged mental

\footnotetext{
* Address for correspondence: Department of Psychiatry, Douglas Mental Health University Institute, McGill University, 6875, boulevard LaSalle, Verdun (Québec), H4H 1R3, Canada.

(Email: robert.whitley@mcgill.ca)
}

illness in the non-Western world during the colonial period. This generally involved the construction and operation of a centralised mental hospital in the administrative centre of a colonial jurisdiction (Hickling, 1994). Such psychiatric activity was part of wider health improvement efforts described contemporaneously as 'tropical medicine', delivered principally by colonial medical officers or missionaries. The phrase 'tropical medicine', tainted by associations with colonialism, was replaced in the later decades of the 20th century with the phrase 'international health'. This was characterised by a public health approach with a focus on the reduction of communicable diseases in developing countries. Psychiatry and mental health remained a peripheral concern to 'international health' (de Jong, 2014).

This perspective has changed as many developing countries have recently made the epidemiological transition, with non-communicable diseases replacing communicable diseases as the principal populationlevel disease burden. This led to greater endeavours to address the burden of non-communicable diseases by various sectors, including governments, foreign aid agencies and non-governmental organisations. This expansion of activity has coincided with another 
name change in the 21st century: 'Global health'. Understanding this historical framework is essential to understanding the concept, conflicts and controversies surrounding 'Global Mental Health' (GMH).

\section{GMH: the concept}

The term 'Global Mental Health' (GMH) may seem selfexplanatory; however, it is a carefully chosen phrase, and stands in opposition to previous descriptors as well as other possible alternatives. The term 'global' has replaced outmoded words such as 'tropical', and even the more recent concept of 'international' health. This is partly a political statement, implying that anyone with mental illness anywhere on the globe deserves attention, regardless of race, creed, caste or location (Kirmayer \& Pedersen, 2014). Invocation of the word 'global', also associates GMH with other inspirational statements of the 'global', for example the Universal Declaration of Human Rights (Kleinman, 2009). Indeed $\mathrm{GMH}$ draws much inspiration and support from another 'global' body, the World Health Organization (WHO, 2010, 2013; Saxena et al. 2013). Relatedly, the term 'mental health' has been carefully chosen instead of 'psychiatry'. This makes the endeavour more inclusive, implicitly acknowledging that other academic disciplines can play a role in furthering GMH (Patel, 2014).

It is important to note that GMH is much more than a rarefied academic concept. It is also a movement with proponents, adherents, opponents, an ideology and core activities. Like all movements, it has leaders, meetings, publications, websites and a level of organisation allowing it to function and expand. The birth of the GMH movement can be traced to London, 2007, when researchers led by Vikram Patel (London School of Hygiene and Tropical Medicine) and Martin Prince (King's College London) published a series of papers in The Lancet on the topic (Chisholm et al. 2007; Patel et al. 2007a, b; Prince et al. 2007). Indeed Lancet editor Richard Horton titled his commentary 'launching a new movement for mental health' (Horton, 2007).

This was accompanied by other outreach efforts, including the formation of an official 'movement for $\mathrm{GMH}^{\prime}$, consisting of various university departments and other organisations (Patel et al. 2011c). This is described at www.globalmentalhealth.org. The stated aims of the Movement for GMH are to improve services for people living with mental health problems and psychosocial disabilities worldwide, especially in low- and middle-income countries where effective services are often scarce'. This aim distinguishes the GMH movement from the decades of work within cultural psychiatry and medical anthropology that sought to understand local conceptions of mental distress and healing (Kirmayer \& Pedersen, 2014).

\section{GMH: the rationale}

The rationale for the new GMH movement derives from various sources. Historically, it derives from a cognizance that throughout the history of the developing world, addressing mental illness has been accorded a very low priority. In the colonial era, formal health care was unjustly distributed, often focused on ensuring the health and well-being of colonial administrators and European settlers. The health care of the indigenous population was a secondary interest to the medical establishment, unless it endangered white hegemony or social stability (Hickling, 1994).

Despite independence, the neglect of mental health issues persisted during the post-colonial era. Mental health policies and practices remained stagnant, partially due to other pressing problems. These included war, natural disasters, infectious disease epidemics, famine and drought. As such, much governmental and non-governmental action was focused on addressing these problems. Again mental health remained a peripheral issue. As such, GMH could be considered an effort to right a persistent historic wrong: the continued neglect of mental illness in developing countries; what Kleinman (2009) calls 'a failure of humanity'.

Relatedly, it should be noted that the Western psychiatric establishment of the day either supported such neglect or was at best indifferent to mental illness in the non-Western world. Much contemporary psychiatric 'scholarship' (and popular opinion) depicted mental illness as a disease caused by maladaptation to 'civilisation' and modernity (Freud, 1930; Gordon, 1936; Jung, 1964). As such, it was commonly believed that Africans and other non-Western people were protected from mental illnesses due to the posited absence of civilisation therein. Indeed Carothers (1953) famously stated that 'the African is a happy savage' protected from psychic conflict due to an untamed environment and inexperience of modernity. Such environmental explanations interacted with biological scientific racism, with Carothers (1951) stating that Africans had 'idle' frontal lobes which made them less susceptible to mental illness.

This neglect continued into the 21st century, as health advocates continued to concentrate their efforts on reducing the burden of communicable disease, focusing their energy on vaccinations, improved sanitation and infectious disease control. This led to improvements in public health allowing a substantial 
proportion of these countries to make the epidemiological transition in recent years. This has led to an increased burden of non-communicable disease as a proportion of the total disease burden (Alonso et al. 2013). As a consequence, mental illness, for so long neglected as a peripheral medical concern, has taken a new prominence.

\section{The GMH problem: the 'treatment gap'}

Proponents of GMH have relied on pre-existing studies to define the core GMH problem, which has been succinctly defined in three words: 'the treatment gap' (Patel et al. 2010). This is an estimate of the proportion of people with a supposed mental illness who are actually receiving formal mental health treatment, estimated to be between 10 and 25\% (Patel et al. 2010; WHO, 2011). In particular, the foundation of GMH is based on numerous studies that converge to indicate that: (i) the burden of mental illnesses such as schizophrenia in developing countries are roughly equal to those found in Western countries, and increasing as a proportion of total disease burden (WHO, 2011; Alonso et al. 2013); (ii) the vast majority of these mental illnesses go untreated by the formal mental health system (Patel \& Prince, 2010); (iii) in response to mental health issues, many sufferers resort to traditional or spiritual healers and healing (Kleinman, 1980; de Jong, 2014); (iv) the impact of mental illness in these settings can be devastating, in terms of symptoms, stigma and functional impairment (Prince et al. 2007); (v) the availability and penetration of formal mental health treatment, and the ratio of mental health clinicians to the population, remain exceedingly low (Kakuma et al. 2011). This results in a substantial 'treatment gap'.

This knowledge was the departure point for the $\mathrm{GMH}$ movement, leaving it free to focus its energy on raising awareness of the treatment gap and developing solutions. This has been done through a series of audacious steps. In addition to the 2007 Lancet series, key figures have continued to publish regular papers in prominent journals outlining the $\mathrm{GMH}$ agenda and calling for more action. This includes further articles in The Lancet (e.g., Patel et al. 2011a), Nature (Collins et al. 2011) and JAMA (Patel \& Prince, 2010). Secondly, funding agencies have been persuaded to lend substantial financial support to GMH action and research initiatives through specific funding opportunities. These include funding streams made available by Grand Challenges Canada, the Wellcome Trust, the U.K Department for International Development (DfID) and the U.S. National Institutes of Health (Patel, 2012; Bemme \& D'Souza, 2014). Thirdly, a broad alliance of interested parties across the world has been formed and solidified to address GMH issues (see www.globalmentalhealth.org). As a movement, GMH has been phenomenally successful in promoting its agenda and gaining visibility in a relatively short space of time.

\section{The GMH solution: scale-up and task-shifting}

Given that GMH is still in its infancy, its amassed empirical work remains modest in comparison with other areas of psychiatry, with many of its key papers being editorials rather than research studies (e.g., Prince et al. 2007; Collins et al. 2011). That said, a respectable amount of empirical work has been conducted since 2007. Much of this has focused on developing and evaluating systems or interventions that can address the 'treatment gap'.

The most oft-cited potential solution to this problem has become known as the 'scale-up' of evidence based practices and services in developing countries. This involves identifying cost-effective evidence-supported practices and services that could feasibly be made more widely available in developing countries (Chisholm et al. 2007). The WHO took a lead in this process through its Mental Health Gap Programme, which published an intervention guide for 'mental, neurological and substance use disorders in nonspecialised health settings' based on extensive literature review (WHO, 2010). This gave guidance for the treatment of disorders in developing countries, including depression, psychosis and bipolar disorder, suggesting pharmacological as well as psychosocial interventions.

Such activity begs a further question, namely, who is going to deliver such interventions given the paucity of personnel trained in mental health care in developing countries? This has involved widespread examination of what has become known in the literature as 'task-shifting'. Task-shifting involves training locally based non-specialists to deliver certain mental health interventions, mainly psychosocial ones or 'talking therapies' (Fulton et al. 2011). These non-specialists are generally Lay Health Workers (LHWs). These are local community health workers with some health training, ubiquitous across the developing world. Numerous studies, including several completed and ongoing randomised controlled trials, have examined the ability of specially trained LHWs to effectively deliver interventions such as Cognitive Behavioural Therapy or Interpersonal Psychotherapy (Rahman et al. 2008; Patel et al. 2011b). Key findings from such studies are that 'task-shifting' to LHWs is not only feasible, but also effective. Trial results consistently 
showed significantly better recovery rates in the intervention group than those receiving a psychosocial placebo (unstructured LHW visits).

Efforts have also been made to develop and outline suitable training programmes and desirable competencies for LHWs, as well as common deficiencies that need to be addressed (Fulton et al. 2011; Balaji et al. 2012). So far, growing evidence about effective taskshifting of psychosocial interventions to LHWs could be considered the major research finding of the GMH enterprise.

\section{GMH: the critique}

GMH has come under a sustained attack from a variety of scholars. Much like the anti-psychiatry attack in the 1960s, this attack has come most vociferously from other psychiatrists (rather than the oft-blamed social scientists) such as Derek Summerfield and Suman Fernando.

A central critique is that GMH activities are aggressively and erroneously imposing the Western model of mental illness on the entire globe in a top-down manner. This has been interpreted as an act of cultural imperialism reminiscent of colonial era 'tropical medicine' where indigenous knowledge and practice was ridiculed and marginalised (Summerfield, 2008, 2013; Fernando, 2011). It is also claimed that this is scientifically invalid, inasmuch as Western concepts of mental illness are posited to be cultural constructs inapplicable elsewhere (Summerfield, 2002). This argument also claims that GMH elides the various modalities of healing present in non-Western cultures, which may be psychologically adaptive and curative (Sax, 2014).

For example, much care of people with psychological troubles in developing countries is provided within the family, a spiritual community or by traditional healers (Kleinman, 1980). As a consequence, the process of labelling and separation of people with 'mental illness' from wider society, so detrimental to recovery and social integration in the west, appears less pronounced in developing countries. Indeed, much evidence suggests that these inclusive processes have a strong curative and therapeutic value. Results from the wellknown International Pilot Study of Schizophrenia show that functional outcomes (such as employment) and recovery rates are better in developing countries than the developed world (Leff et al. 1992). This has been partially attributed to international variations in the nature and degree of stigma and separation (Thara \& Srinivasan, 2000; Hopper et al. 2007). This suggests that traditional modalities of healing involving the family, social normalisation and spiritual approaches may play an important role in recovery. However, spirituality, traditional healers and traditional healing approaches are generally absent in the GMH literature and agenda, which focuses on neatly packaged Western-derived pharmacology or psychosocial interventions (Fernando, 2012).

This relates to another critique. This is the fear that GMH could be an unwitting Trojan horse for the mass medicalisation of people in the developing countries, paving the way for corporate interests (i.e., 'Big Pharma') to repackage social suffering as a medical problem and exploit potential new markets (Fernando, 2011). This argument runs as follows: firstly, alien concepts and categories such as post traumatic stress disorder (PTSD) or depression are introduced into new places; secondly, people who were previously categorised as having manageable 'problems in living' are identified and relabelled as 'mentally ill'; thirdly, these people are then offered medications developed in the Western world. This concern is fuelled by the fact that the WHO MHGap Programme recommends a strong role for psychotropic medication in the developing world (WHO, 2010).

In response, GMH leaders such as Patel (2014) claims that this argument basically traduces $\mathrm{GMH}$, inasmuch as most GMH interventions hitherto have been psychosocial or talking therapies. Patel (2014) also states that 'I have never received personal funding from any pharmaceutical company'. That said, GMH is clearly a top-down elite-led movement rather than a bottom-up grassroots movement, formed and led by Western-educated clinicians (Bemme \& D'Souza, 2014). The overlap between their preferred models and interventions and those of ordinary people on the ground continues to be questioned in the literature (Swartz, 2012).

Another critique relates to the nature of 'partnerships' in GMH. Crane (2011, 2013) and others have argued that global health in general is not based on a true collaborative partnership between north and south. In contrast, she argues that Western universities and NGOs are engaged in a somewhat undignified 'scramble for Africa' for reasons of prestige, public relations and competition with other Western universities. Short-term medical missions, study abroad programmes, university partnerships, student internships and the like provide ample opportunity for students and faculty from Western universities to travel and bring honour to their home universities. However, Crane $(2011,2013)$ notes that these programmes are often unidirectional and questions how far they benefit the communities they aim to serve.

A final critique relates to the social and cultural determinants of health. It has been argued that GMH is anthropologically and sociologically naïve, inasmuch as a considerable amount of the social and 
mental suffering experienced in developing countries can be attributed to adverse social conditions, structural violence, poverty, war, famine and inequality (Kirmayer \& Pedersen, 2014). Summerfield (2008) argues that the natural human response to such phenomena is a level of everyday social suffering that may superficially appear like 'depression' but is in fact not a mental illness but 'a normal reaction to their circumstances' ( $p$ 993). Rather than focusing attention on the causes of such social suffering, GMH is perceived to be providing medical solutions to non-medical problems, thereby unwittingly acquiescing in the social status quo. In response, Patel (2014) argues that many GMH interventions include attention to social conditions, including addressing livelihood skills as well as raising awareness about rights and community resources.

That said, it is worth noting that GMH has avoided the critical or radical post-colonial tradition in psychiatry which argues that much social suffering and emotional distress is based on social and ethnic hegemony and domination, which must be combatted to improve mental health (e.g., Fanon, 1952, 1963; Grier \& Cobbs, 1968; Welsing, 1991). Even in Western countries, much attention has been given to the negative health impact of social stratification and inequality (Marmot, 2005; Wilkinson \& Pickett, 2006). This is also a tradition within wider public health and epidemiology research (e.g., Farmer, 2004; Tol et al. 2013). Indeed, a recent editorial in The Lancet (2014) noted that health advocates have avoided confronting uncomfortable truths in developing countries such as the 'institutionalised inequality' of the Indian caste system and its deleterious effect on the health of 'low-caste' people. Controversial issues such as these, in addition to issues such as sectarianism, war, racism and social elitism, have been avoided by GMH, which has preferred to focus its activities on the scale-up and task-shifting of narrow, Western-developed interventions (Summerfield, 2012).

The discipline of medical anthropology provides one approach to link social, economic and political forces to local experiences of (individual and social) suffering and distress (Janes \& Corbett, 2009). Intensified partnerships between medical anthropologists and GMH leaders (most of whom are trained psychiatrists) may be a fruitful approach to resolve these issues.

\section{Conclusion}

GMH stormed onto the psychiatric scene in 2007. Since then, its impressive rise has led to much research and action. Core research findings include the importance of scale-up of evidence-based interventions to increase population coverage, as well as the role of task-shifting delivery of such interventions to LHWs. Key actions include putting mental health on the agenda in developing countries, as well as ensuring that Western-funding agencies devote financial resources to GMH research and action. As stated, GMH is not without its critics. Many suggest that $\mathrm{GMH}$ is colonial medicine come full circle, a modern day version of Kipling's 'White Man's Burden', full of good intentions, but also a form of anthropologically uninformed cultural imperialism. As such, GMH is perceived to involve the top-down imposition of Western psychiatric models and solutions, rather than the careful attention to bottom up notions of suffering and healing so beloved of cultural psychiatrists and medical anthropologists. Whichever, the rise of GMH has opened a window of opportunity for those interested in mental health in developing countries. The debate will continue, likely more vigorously, as time progresses.

\section{Acknowledgements}

None.

\section{Financial support}

None.

\section{Statement of interest}

None.

\section{References}

Alonso J, Chatterji S, Yanling H (2013). The Burdens of Mental Disorders: Global Perspectives from the WHO World Mental Health Surveys. Cambridge University Press: New York, NY.

Balaji M, Chatterjee S, Koschorke M, Rangaswamy T, Chavan A, Dabholkar H, Dakshin L, Kumar P, John S, Thornicroft G, Patel V (2012). The development of a lay health worker delivered collaborative community based intervention for people with schizophrenia in India. BMC Health Services Research 12, 42.

Bemme D, D'Souza NA (2014). Global mental health and its discontents: an inquiry into the making of global and local scale. Transcultural Psychiatry 51, 850-874.

Carothers JC (1951). Frontal lobe function and the African. Journal of Mental Science 97, 12-48.

Carothers JC (1953). The African Mind in Health and Disease. World Health Organization: Geneva.

Cartwright SA (1851). Report on the diseases and physical peculiarities of the Negro race. New Orleans Medical and Surgical Journal 1851, 691-715.

Chisholm D, Flisher AJ, Lund C, Patel V, Saxena S, Thornicroft G, Tomlinson M (2007). Scale up services for mental disorders: a call for action. Lancet 370, 1241-1252.

Collins PY, Patel V, Joestl SS, March D, Insel TR, Daar AS, Anderson W, Dhansay MA, Phillips A, Shurin S, Walport M, Ewart W, Savill SJ, Bordin IA, Costello EJ, Durkin M, Fairburn C, Glass RI, Hall W, Huang Y, 
Hyman SE, Jamison K, Kaaya S, Kapur S, Kleinman A, Ogynniyi A, Otero-Ojeda A, Poo MM, Ravindranath V, Sahakian BJ, Saxena S, Singer PA, Stein DJ (2011). Grand challenges in global mental health. Nature 475, 27-30.

Crane J (2011). Scrambling for Africa? Universities and global health. Lancet 377, 1113.

Crane J (2013). Scrambling for Africa: AIDS, Expertise and the Rise of American Global Health Science. Cornell University Press: Ithaca, NY.

de Jong JT (2014). Challenges of creating synergy between global mental health and cultural psychiatry. Transcultural Psychiatry 51, 806-828.

Fanon F (1952). Black Skin, White Masks (Orig. Peau Noire, Masques Blancs). Éditions du Seuil: Paris, France.

Fanon F (1963). The Wretched of the Earth (Farrington C, Trans.). Grove Press: New York, NY.

Farmer P (2004). An anthropology of structural violence. Current Anthropology 45, 305-325.

Fernando GA (2012). The roads less traveled: mapping some pathways on the global mental health research roadmap. Transcultural Psychiatry 49, 396-417.

Fernando S (2011). A global mental health program or markets for 'Big Pharma'. Open Mind 168, 22.

Freud S (1930). Civilization and its Discontents (Orig. Das Unbehagen in der Kultur). Internationaler Psychoanalytischer Verlag Wien: Vienna, Austria.

Fulton BD, Scheffler RM, Sparkes SP, Auh EY, Vujicic M, Soucat A (2011). Health workforce skill mix and task shifting in low income countries: a review of recent evidence. Human Resources for Health 9, 1.

Gordon H (1936). An enquiry into the correlation of civilization and mental disorders in the Kenyan native. East African Medical Journal 12, 327-335.

Grier WH, Cobbs PM (1968). Black Rage. Basic Books: New York, NY.

Hickling FW (1994). Community psychiatry and deinstitutionalization in Jamaica. Hospital \& Community Psychiatry 45, 1122-1126.

Hopper K, Harrison G, Janca A, Sartorius N (2007). Recovery from Schizophrenia: An International Perspective: A Report from the WHO Collaborative Project, the International Study of Schizophrenia. Oxford University Press: New York, NY.

Horton R (2007). Launching a new movement for mental health. Lancet 370, 806.

Janes CR, Corbett KK (2009). Anthropology and global health. Annual Review of Anthropology 38, 167-183.

Jung C (1964). Civilization in Transition (Collected Works of C. G. Jung, Vol. 10). Routledge: London, UK.

Kakuma R, Minas H, van Ginneken N, Dal Poz MR, Desiraju K, Morris JE, Saxena S, Scheffler RM (2011). Human resources for mental health care: current situation and strategies for action. Lancet 378, 1654-1663.

Kirmayer LJ, Pedersen D (2014). Toward a new architecture for global mental health. Transcultural Psychiatry 51, 759-776.

Kleinman A (1980). Patients and Healers in the Context of Culture: An Exploration of the Borderland between Anthropology, Medicine and Psychiatry (Comparative Studies of Health Systems and Medical Care, Vol. 3). University of
California Press: Berkeley and Los Angeles, California, London, UK.

Kleinman A (2009). Global mental health: a failure of humanity. Lancet 374, 603-604.

Kraepelin E (1921). Manic-Depressive Insanity and Paranoia (Barclay RM, Trans.). E \& S Livingstone: Edinburgh, UK.

Lancet (2014). The health of India: a future that must be devoid of caste. Lancet 384, 1901.

Leff J, Sartorius N, Jablensky A, Korten A, Ernberg G (1992). The International Pilot Study of Schizophrenia: five-year follow-up findings. Psychological Medicine 22, 131-145.

Marmot M (2005). Social determinants of health inequalities. Lancet 365, 1099-1104.

Patel V (2012). Global mental health: from science to action. Harvard Review of Psychiatry 20, 6-12.

Patel V (2014). Why mental health matters to global health. Transcultural Psychiatry 51, 777-789.

Patel V, Prince M (2010). Global mental health: a new global health field comes of age. Journal of the American Medical Association 303, 1976-1977.

Patel V, Araya R, Chatterjee S, Chisholm D, Cohen A, De Silva M, Hosman C, McGuire H, Rojas G, van Ommeren $\mathbf{M}$ (2007a). Treatment and prevention of mental disorders in low-income and middle-income countries. Lancet 370, 991-1005.

Patel V, Flisher AJ, Hetrick S, McGorry P (2007b). Mental health of young people: a global public-health challenge. Lancet 369, 1302-1313.

Patel V, Maj M, Flisher AJ, De Silva MJ, Koschorke M, Prince M, WPA Zonal and Member Society Representatives (2010). Reducing the treatment gap for mental disorders: a WPA survey. World Psychiatry 9, 169-176.

Patel V, Boyce N, Collins PY, Saxena S, Horton R (2011a). A renewed agenda for global mental health. Lancet 378, 1441-1442.

Patel V, Chowdhary N, Rahman A, Verdeli H (2011b). Improving access to psychological treatments: lessons from developing countries. Behaviour Research and Therapy 49, 523-528.

Patel V, Collins PY, Copeland J, Kakuma R, Katontoka S, Lamichhane J, Naik S, Skeen S (2011c). The movement for global mental health. British Journal of Psychiatry 198, 88-90.

Prince M, Patel V, Saxena S, Maj M, Maselko J, Phillips MR, Rahman A (2007). No health without mental health. Lancet 370, 859-877.

Rahman A, Malik A, Sikander S, Roberts C, Creed F (2008). Cognitive behaviour therapy-based intervention by community health workers for mothers with depression and their infants in rural Pakistan: a cluster-randomised controlled trial. Lancet 372, 902-909.

Sax W (2014). Ritual healing and mental health in India. Transcultural Psychiatry 51, 829-849.

Saxena S, Funk M, Chisholm D (2013). World health assembly adopts comprehensive Mental Health Action Plan 2013-2020. Lancet 381, 1970-1971.

Shorter E (1997). A History of Psychiatry. John Wiley and Sons: New York. 
Summerfield D (2002). ICD and DSM are contemporary cultural documents. British Medical Journal 324, 914.

Summerfield D (2008). How scientifically valid is the knowledge base of global mental health? British Medical Journal 336, 992-994.

Summerfield D (2012). Afterword: against "global mental health". Transcultural Psychiatry 49, 519-530.

Summerfield D (2013). "Global mental health" is an oxymoron and medical imperialism. British Medical Journal 346, 3509.

Swartz L (2012). An unruly coming of age: the benefits of discomfort for global mental health. Transcultural Psychiatry 49, 531-538.

Thara R, Srinivasan TN (2000). How stigmatizing is schizophrenia in India? International Journal of Social Psychiatry 46, 135-141.
Tol WA, Rees SJ, Silove DM (2013). Broadening the scope of epidemiology in conflict-affected settings: opportunities for mental health prevention and promotion. Epidemiology and Psychiatric Sciences 22, 197-203.

Welsing FC (1991). The ISIS Papers. C.W Publishing: Washington, DC.

Wilkinson RG, Pickett KE (2006). Income inequality and population health: a review and explanation of the evidence. Social Sciences and Medicine 62, 1768-1784.

World Health Organization (2010). mhGAP Intervention Guide for mental, neurological and substance use disorders in non-specialized health settings. Geneva, Switzerland.

World Health Organization (2011). Mental Health Atlas 2011. Geneva, Switzerland.

World Health Organization (2013). Comprehensive Mental Health Action Plan 2013-2020. Geneva, Switzerland. 